\title{
OBTAINING LAMINATED ALUMINUM COMPOSITES WITH A GRADIENT STRUCTURE BASED ON ASYMMETRIC DEFORMATION
}

\author{
Olesya BIRYUKOVA ${ }^{1}$, Alexander PESIN ${ }^{1}$, Denis PUSTOVOYTOV ${ }^{1}$, Anna KOZHEMIAKINA ${ }^{1}$, \\ Leonid NOSOV ${ }^{1}$ \\ ${ }^{1}$ Nosov Magnitogorsk State Technical University, Magnitogorsk, Russia, fimapatisonchik@inbox.ru, \\ biryukova.mgtu@gmail.com, pesin@bk.ru, pustovoitov den@mail.ru, kozhemiakina.a@yandex.ru
}

https://doi.org/10.37904/metal.2021.4133

\begin{abstract}
Nowadays the use of laminated composites in various industries is becoming popular. Unlike single layer materials, laminated materials are characterized as more durable, corrosion resistant, technological materials for the production of parts for various purposes. The research considers laminated materials made of aluminum alloys. It is proposed to use aluminum alloys of $1 \mathrm{xxx}, 2 \mathrm{xxx}$ and $5 \mathrm{xxx}$ series. Products made of aluminum laminated composites will be widespread in such industries as: 1) Aircraft construction. Aviation equipment has high requirements for mechanical and operational properties: aircraft must withstand heavy loads at constant temperature drops, be light and resist the corrosion. 2) Space construction. There is an actual problem of technogical contamination due to explosions of space objects, as well as the possibility of widespread use of hydrogen liquefied fuel, which is not common at present. Also it is necessary to increase the strength of metallic materials, trying to reduce their weight to save fuel. 3) Automotive industry. Also it is worth touching on the environmental problem: with an increase in the weight of the car structure, the level of fuel consumption increases. With a decrease in the weight of the car while maintaining the strength characteristics, it will not only improve the environmental situation, but also make the car safer in operation. In the works of Russian and foreign scientists, insufficient attention is paid to the technologies for processing aluminum alloys using asymmetrical deformation. This is a confirmation of the incomplete study of this problem and is a task of current interest.
\end{abstract}

Keywords: Asymmetric deformation, aluminum alloy, equivalent deformation, severe plastic deformation

\section{INTRODUCTION}

Today laminated metals are an alternative substitution for alloyed monometals. Alloys of such kind are widely used in various industries: from space technology to the chemical industry. They have special physical and mechanical properties, because they combine the parameters of two or more components. High corrosion resistance, commensurate strength and plasticity, manufacturability will allow laminated materials to withstand not only high loads, but also exploitation conditions in corrosive environments without significant changes in strength characteristics. Methods for obtaining laminated materials are diverse: welding, casting, surfacing and plastic deformation. The last mentioned method is most common in metal forming, such as stamping, forging or rolling. However, there are difficulties in preparing the surface of metals for a durable joint and the formation of transitional or diffusion layers. The complexity of obtaining a durable transitional layer depends on the types of joint metals, their ability to form protective oxide films, the possibility of removing films, protecting the surface from their formation and destruction during plastic deformation. Joining processes can also be accompanied by the formation of intermetallics, which adversely affects the properties.

In this regard, one of the most suitable materials for the production of laminated composites is aluminum and its alloys. When welding two types of aluminum alloys by pressure, it is important to choose the right method 
for cleaning the surface from external contamination and oxide films, as well as the value of reductions and heat treatment.

The offered aluminum sheet laminated composites can find their application in automobile, aircraft and rocket industry. In this case, environmental issues are acute. It is necessary to create such constructions that will reduce the weight of the finished product. This will reduce fuel consumption in the listed industries. Moreover it will reduce emissions of harmful substances into the atmosphere. Correctly selected processing will allow obtaining a high level of strength and plastic characteristics in aluminum alloys. Such type of processing is the methods of severe plastic deformation (SPD).

SPD in research is presented in the form of asymmetric deformation. It includes asymmetric rolling, asymmetric accumulative rolling and asymmetric cryogenic rolling [1-3]. The purpose of these methods is to obtain a nanoor ultrafine-grained gradient structure. The properties of the metal after such processing show an increase in strength, wear resistance, combined with preservation or even an increase in the value of ductility. Moreover, it becomes possible to process long products, which was rather difficult to produce by other SPD methods, for example, with equal-channel angular pressing (ECAP) or high pressure torsion (HTP) [4-11].

However, asymmetric deformation methods have some limitations. Large shear deformation can lead to high heterogeneity. In turn it can lead to the formation of defects - flaws, cracks and pores. In the laminated material, additional delamination may appear along the weld. To solve these problems, it is necessary to select technological regimes, according to which the coefficients of friction, rolls speed ratio, preliminary heat treatment (heating or high-speed cooling) will correspond to defect-free processing and rectilinear exit of the metal from the deformation zone (taking into account asymmetry).

\section{RESEARCH METHOD AND USED MATERIALS}

The aim of this work is to analyze the model of asymmetric deformation of aluminum alloys. We ought to determine the parameters that simultaneously allow to ensure the straightness of the exit from the deformation zone and to get the required gradient structure of each of its constituent layers. In case of severe plastic deformation (in paper there are asymmetric rolling of sheet laminated material and asymmetric accumulative rolling), it is necessary to comply with the structure transformations. It includes the achievement of equivalent deformation values more than 3 [12], which will allow obtaining high values of strength and ductility. This is due to the formation of shear and rotation angles, which give an increase in the shear deformation with the formation of a simple and pure shears, and obtaining a fine-grained structure (the level of ultrafine-grained and nano).

The analysis was carried out with the use of Deform 2D software package. The research shows the example of asymmetric deformation of aluminum alloys 1070 and 5083, the chemical composition of which is presented (Table 1).

Table 1 Chemical composition of aluminum alloys 1070 and 5083

\begin{tabular}{|c|c|c|c|c|c|c|c|c|c|}
\hline Alloy & $\mathbf{S i}$ & $\mathbf{F e}$ & $\mathbf{C u}$ & $\mathbf{M n}$ & $\mathbf{M g}$ & $\mathbf{C r}$ & $\mathbf{Z n}$ & $\mathbf{T i}$ & $\mathbf{A l}$ \\
\hline 1070 & 0.15 & 0.16 & 0.01 & 0.03 & 0.02 & - & 0.04 & 0.01 & 99.7 \\
\hline 5083 & 0.091 & 0.285 & 0.027 & 0.682 & 4.479 & 0.104 & 0.014 & 0.007 & 94.282 \\
\hline
\end{tabular}

The initial material was a laminated sheet composite made of aluminum alloy 5083/1070, with a thickness of $2 \mathrm{~mm}$. Rolling was carried out without tension. The diameter of the absolutely rigid rolls was $250 \mathrm{~mm}$, the coefficient of friction varied from 0.1 to 0.4 . The degree of deformation was assumed to be $50 \%$. The speed of the rolls during symmetric rolling was $1.047 \mathrm{rad} / \mathrm{s}$. The rolls speed ratio during asymmetric deformation varied within the range of $10 \%-50 \%$. The conditions for joining two layers of dissimilar aluminum alloys were defined as "gluing", implying their mechanical welding during deformation. In most models, there is a deviation 
in straightness, which causes bending at both the front and rear ends of the strip. Factors most affecting the bending of the metal: coefficient of friction, the value of rolls speed ratio, the type of material being processed.

\section{RESULTS AND DISCUSSIONS}

The values of the effective strain in the layered sheet composite were analyzed separately for each of its constituent metals, as well as in the middle layer. The calculation of the parameters of the middle layer was carried out by analyzing the middle points of contact between two alloys. The properties of this layer are very different from the alloys of which it is composed. In order to obtain an optimal processing of the metal joint, it is necessary to take into account the peculiarities of both alloys and to exclude the possibility of the defects formation in the middle layer. The main disadvantage of the middle layer in aluminum alloys is the practical impossibility of obtaining the same values of ductility and strength in comparison with the base metals.

Middle layer is deformed less than aluminum alloys 1070, but more than 5083 in the all cases of a rolls speed ratio (Figure 1). For clarity, when formation the graphs, we did not take into account the thickness difference of the layers in the composite and the size of the middle layer. The effective strain was estimated from the points of the deformed mesh located in the same plane.

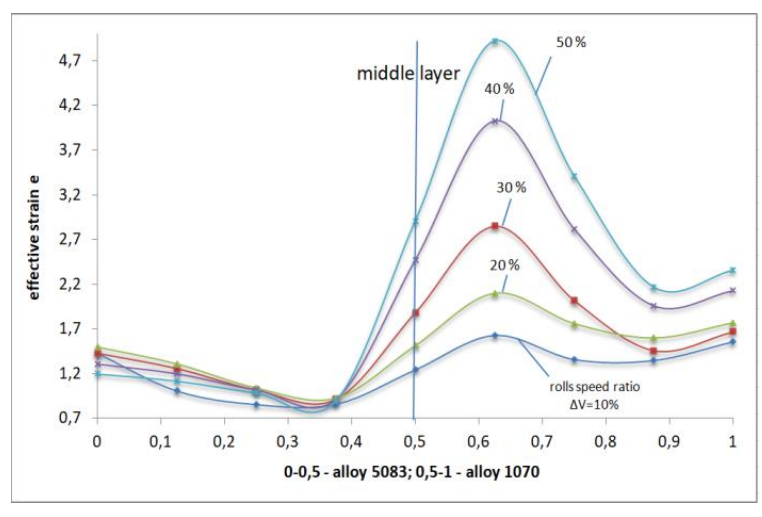

a

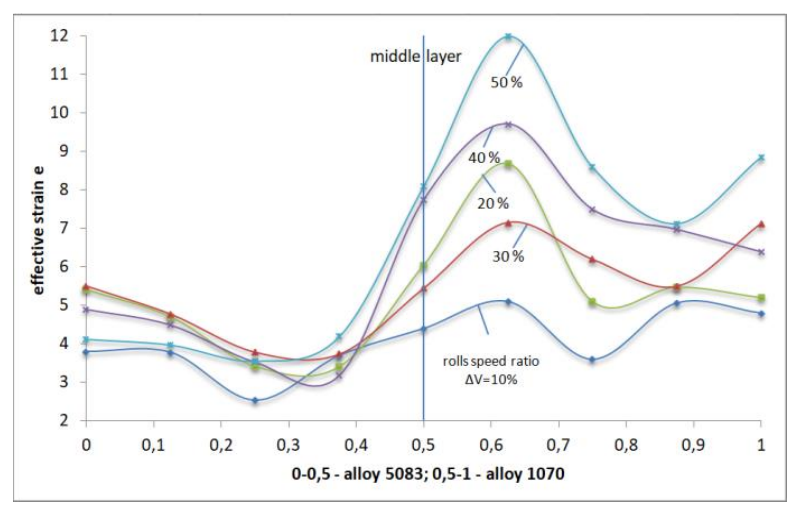

b

Figure 1 The dependence of the effective strain and the Lagrange grid high change during 1 cycle of accumulative roll bonding (a) and 2 cycle of accumulative roll bonding (b) of aluminum composite 5083/1070

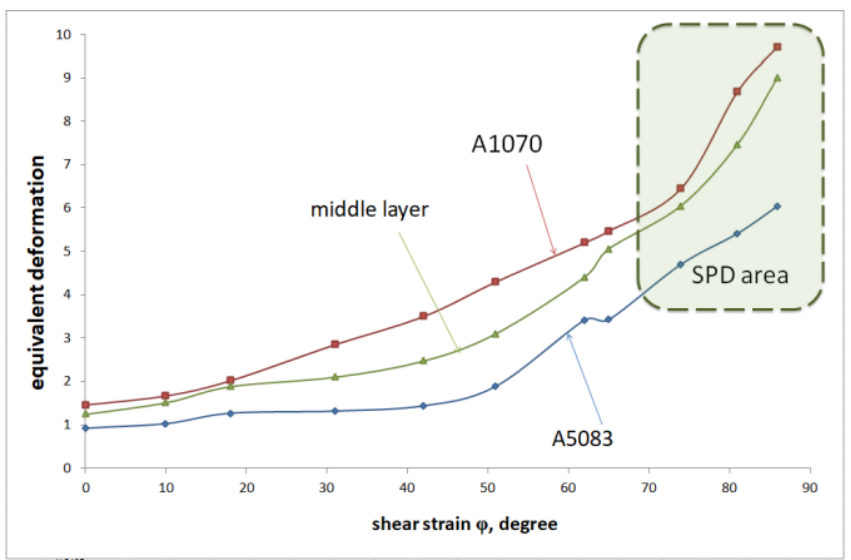

Figure 2 The dependence of the equivalent (accumulated) deformation and the shear angle $\varphi$ during asymmetric deformation of a laminated sheet composite 5083/1070

An assessment was made of the rolls speed ratio and the average value of the effective strain over the thickness of the strip. During the first cycle the deformation indices of the monotonic middle layer change up 
to the values of rolls speed ratio to $50 \%$. But values of effective strain indicate impossibility of getting into the area of severe plastic deformation $(e \leq 3)$. In this case it is necessary to carry out the second processing cycle of accumulative roll bonding to achieve effective strain values to get into the area of severe plastic deformation (in research $e=4 \ldots 8$ in second cycle).

Based on the results of the research, it is possible to determine the ratio of accumulated deformation and shear angle $\varphi$ during asymmetric deformation of an aluminum laminated sheet composite 5083/1070. The threshold value of deformation in conjunction with a shear angle $\varphi$ of more than $65^{\circ}$ makes it possible to determine the rational area of implementation of the process of asymmetric deformation in the regime of severe plastic deformation (Figure 2).

An experimental verification of the obtained results is going on the asymmetric rolling mill 400 of the Zhilyaev Mechanics of Gradient Nanomaterials Laboratory (NMSTU). Presented equipment is a reversible two-roll single stand with individual drive of work rolls with a maximum allowable rolling force of $2500 \mathrm{kN}$ (Figure 3). The work roll diameter is $360 \mathrm{~mm}$ and the maximum rolling speed is $15 \mathrm{~m} / \mathrm{min}$. This mill can process both ferrous (steel) and non-ferrous (aluminum, copper, titanium) metals and alloys.

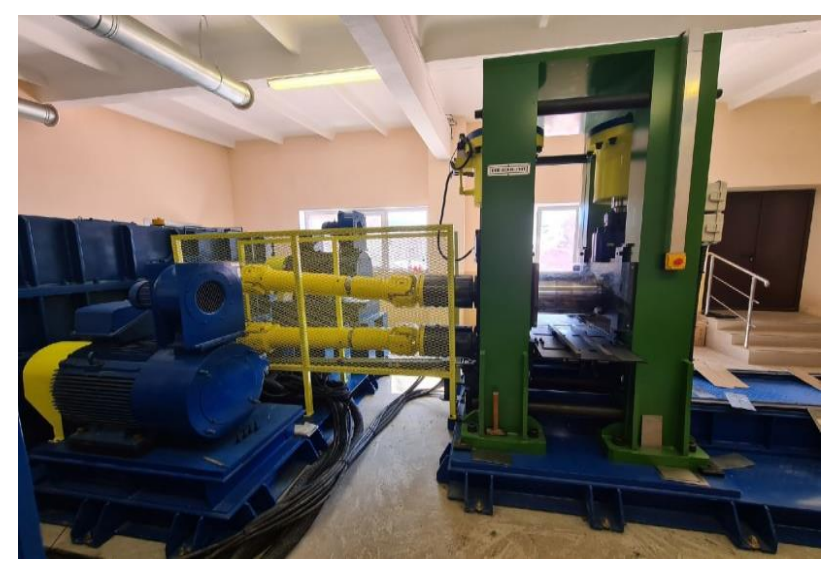

Figure 3 Rolling mill 400 of the Zhilyaev Mechanics of Gradient Nanomaterials Laboratory (NMSTU)

Preliminarily, layered samples of aluminum alloys were obtained by symmetric and asymmetric deformation to confirm the mechanisms of the process. In this case, aluminum alloys of the 5th series were used, of which a layered composite was made. Before processing the laminated material, the surface of the joint was prepared: the samples were cleaned with an abrasive (sanding paper), and also degreased with solvent. The main parameters of rolling of the 5th series are presented in Table 2.

Table 2 Input and output parameters of processing aluminum alloys of the 5th series on the asymmetric rolling mill 400

\begin{tabular}{|c|c|c|c|c|c|c|c|}
\hline Sample & $\begin{array}{c}\text { No of } \\
\text { cycle }\end{array}$ & $\begin{array}{c}\text { Initial } \\
\text { thickness, } \mathbf{m m}\end{array}$ & $\begin{array}{c}\text { Rolling } \\
\text { force, } \mathbf{k N}\end{array}$ & $\begin{array}{c}\text { Roll gap, } \\
\mathbf{m m}\end{array}$ & $\begin{array}{c}\text { Speed of } \\
\text { top roll, } \\
\text { rpm }\end{array}$ & $\begin{array}{c}\text { Speed of } \\
\text { bottom roll, } \\
\text { rpm }\end{array}$ & $\begin{array}{c}\text { Thickness } \\
\text { after rolling, } \\
\text { mm }\end{array}$ \\
\hline 1 & 1 & 4 & 912 & 2 & 4 & 4 & 2.1 \\
\hline 2 & 1 & 4 & 490 & 2 & 4 & 2.2 & 2.0 \\
\hline 3 & 1 & 4 & 490 & 1.9 & 4 & 2.1 & 1.9 \\
\hline 4 & 2 & 3.8 & 509 & 1.8 & 4 & 2.2 & 1.8 \\
\hline 5 & 1 & 4 & 490 & 1.8 & 4 & 2.1 & 1.9 \\
\hline 6 & 2 & 3.8 & 372 & 1.8 & 4 & 2.1 & 1.8 \\
\hline
\end{tabular}


As a result, sample 1 was destroyed during processing, the metal layers were not welded to each other, in addition, a gust formed in the middle of the sample (Figure 4 a). Asymmetric rolling is characterized not only by a decrease in the formation of defects (all samples showed good pressure weldability), but also by a decrease in rolling forces. When processing samples 1 (with a symmetric case) and 2 (with asymmetry) (Figure $4 \mathrm{~b}$ ), the rolling force decreased by $421 \mathrm{kN}$ (by $46 \%$ ). During the accumulation rolling process (samples 3-6) (Figures $4 \mathrm{c}$, d), the rolling force also noticeably decreased - from $510 \mathrm{kN}$ to $372 \mathrm{kN}$ during processing the 5th series. In this case, the reason for the decrease was cutting the side edges of the sample. In this case, the reduction varied from $50 \%$ to $57 \%$ per pass, and the total degree of reduction was more than $105 \%$ (for 2 cycles). Rolls speed ratio ranged from $45 \%$ to $50 \%$ depending on the pass. After all processing cycles, Brinell hardness test was carried out on the EMCO TEST M4C / R G3 hardness tester.

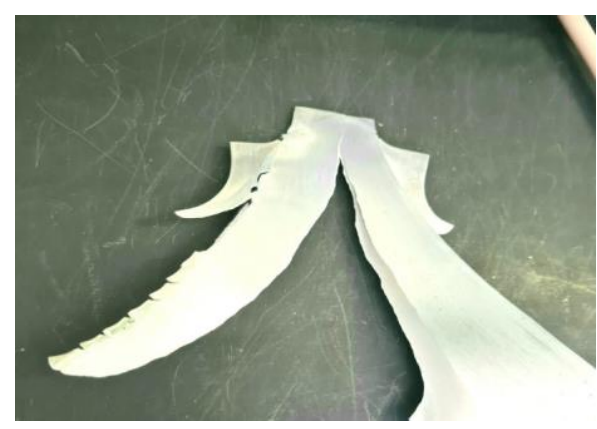

a

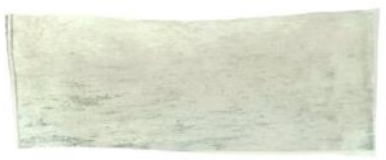

C

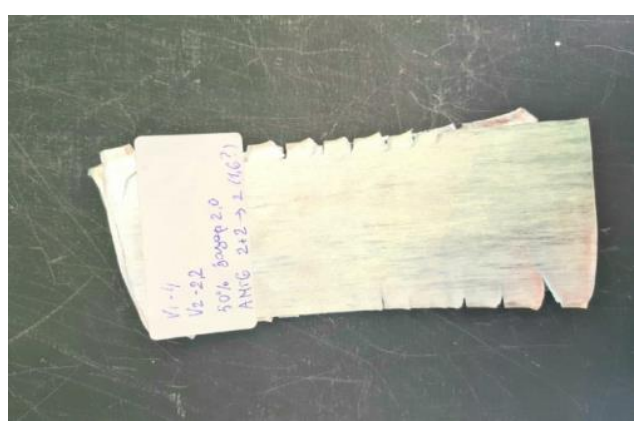

b

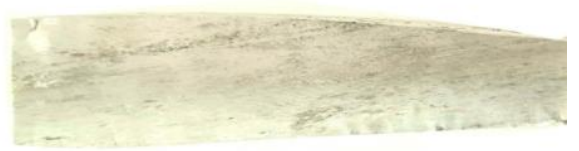

d

Figure 4 Samples of aluminum alloys after symmetric and asymmetric deformation

(a - sample 1, b - sample 2, c - sample 5, d - sample 6)

The average hardness of the processed sample of the 5th series after two accumulative rolling cycles (Figure $4 \mathrm{~d}$ ) was $147 \mathrm{HB}$ from the upper surface, $145 \mathrm{HB}$ from the lower surface, the hardness of the initial material was $81.8 \mathrm{HB}$. So the hardness of the 5 th series alloy increased in 1.8 times.

\section{CONCLUSION}

Computer simulations were carried out using the finite element method. It is shown that the achievement of the maximum value of the equivalent deformation is possible in a contact of sample with the rolls. The values of the equivalent deformation of the transition layer are lower than in the base metals. Getting into the SPD area is possible after the 2 nd cycle of the asymmetric deformation process. A deformation gradient can be achieved in all layers of the material by following the established rules: asymmetric deformation with a friction coefficient of 0.3 ; minimum value of the rolls speed ratio $V_{1} / V_{2}=40 \%$; at least 2 processing cycles are required to get into the SPD area for the processing by the method of asymmetric deformation.

Experimental verification of the obtained results was carried out on the asymmetric rolling mill 400 of the Zhilyaev Mechanics of Gradient Nanomaterials Laboratory (NMSTU). According to preliminary verification results, the mechanisms of asymmetric deformation were confirmed when using samples of the 5th series. It is shown that the use of asymmetry makes it possible to reduce the formation of defects and reduce the rolling forces. When processing samples 1 (with a symmetric case) and 2 (with an asymmetry), the rolling force decreased by $46 \%$. The hardness was measured by the Brinell method on the EMCO TEST M4C / R G3 
hardness tester. The averaged values showed an increase in hardness in 1.8 times after two cycles of asymmetrical deformation.

\section{ACKNOWLEDGEMENTS}

The study was carried out within the framework of the implementation of the Resolution of the Government of the Russian Federation of April 9, 2010 No. 220 (Contract No. 075-15-2019-869 from May 12, 2019); supported by a grant of the Russian Science Foundation (project No. 20-69-46042 of 20.05.2020; funded by RFBR according to the research project № 20-38-90097).

\section{REFERENCES}

[1] YU, H., TIEU, K., and LU, C. Advanced rolling technologies for producing ultrafine-grain/nanostructured alloys. Procedia Engineering. 2014, vol. 81, pp. 96-101.

[2] PESIN, A. Scientific school of asymmetric rolling in Magnitogorsk. Vestnik of Nosov Magnitogorsk State Technical University. 2013, vol. 5, pp. 23-38

[3] LIU, J., WU, Y., WANG, L., WANG, H., KONG, C., PESIN, A., ZHILYAEV, A., YU, H. Fabrication and characterization of high-bonding-strength Al/Ti/Al-laminated composites via cryorolling. Acta Metallurgica Sinica (English Letters). 2020. vol. 33, pp. 871-880.

[4] KAPOOR, R., TYAGI, A., BANERJEE, S. Severe Plastic Deformation of Materials. Mumbai: Materials under Extreme Conditions, 2017, pp. 717-754.

[5] ZRNIK, J., DOBATKIN, S., MAMUZI, I. Processing of metals by severe plastic deformation (SPD)-Structure and mechanical properties respond. Metalurgija. 2008, vol. 47, pp. 211-216.

[6] HUARTE, B., LUIS, C., PUERTAS, I., LEON, J., LURI, R. Optical and mechanical properties of an Al-Mg alloy processed by ECAE. J. Mater. Process. Technol. 2005, vol. 162, pp. 317-326.

[7] IVANISENKO, Y., KULAGIN, R., FEDOROV, V., MAZILKIN, A., SCHERER, T., BARETZKY, B., HAHN, H. High Pressure Torsion Extrusion as a new severe plastic deformation process. Mater. Sci. Eng. A. 2016, vol. 664, pp. 247-256.

[8] KAWASAKI, M., AHN, B., LEE, H.-J., ZHILYAEV, A., LANGDON, T., Using high-pressure torsion to process an aluminum-magnesiumnanocomposite through diffusion bonding. Journal of Materials Research. 2015, vol. 1 , pp. 1-12.

[9] PARK, K., LEE, H.-J., LEE, C., SHIN, D. Effect of post-rolling after ECAP on deformation behavior of ECAPed commercial Al-Mg alloy at 723 K. Mater. Sci. Eng. 2005, vol. 393, pp. 118-124.

[10] ZHILYAEV, A., GARCÍA-INFANTA, J., CARREÑO, F., LANGDON, T., RUANO, O. Particle and grain growth in an Al-Si alloy during high-pressure torsion. Scripta Materialia. 2007, vol. 57, pp. 763-765.

[11] FURUKAWA, M., HORITA, Z., NEMOTO, M., LANGDON, T.G. Review Processing of metals by equal-channel angular pressing. J. Mater. Sci. 2001, vol. 36, pp. 2835-2843.

[12] PUSTOVOYTOV, D., PESIN, A., BIRYUKOVA, O. Finite element analysis of strain gradients in aluminium alloy sheets processed by asymmetric rolling. Procedia Manufacturing. 2018, vol. 15, pp. 129-136. 